Vol. XIX No. 3

\title{
Plants of the Sandhills
}

by Keith F. Best, Swift Current

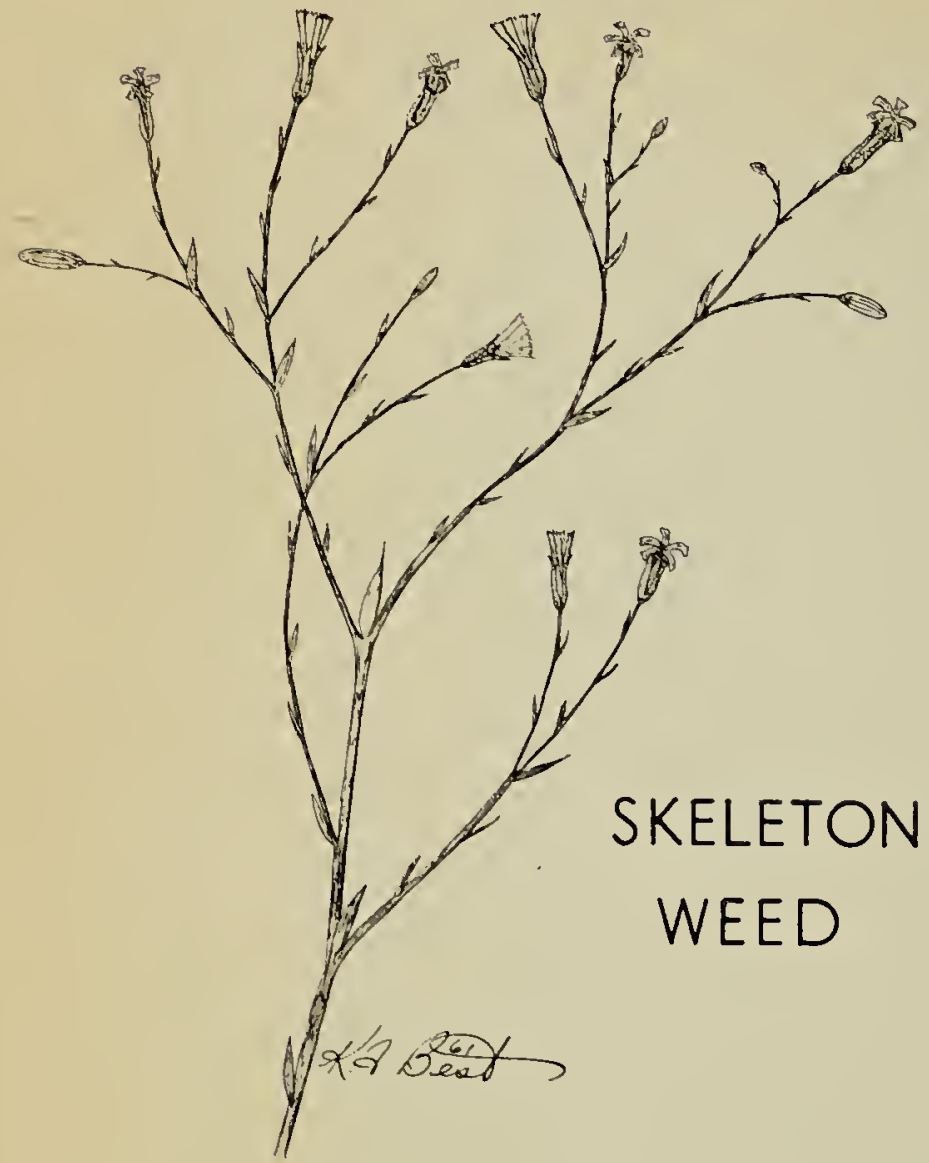

Two additional species usually found growing in the sandhills are the Skeleton Weed and the Largeflowered Yellow Flax illustrated above.

Skeleton Weed (Lygodesmia juncea) is a native plant that has been well known as an obnoxious garden weed since the days of the early settlers. Since that time, it has become a pest in many cultivated fields and pastures. Also called Elkhorn or Devil's Shoe-string, it is a low growing, straggling perennial, from 6 to 18 inches high with the lower leaves narrow and stemlike, while the upper ones are few and reduced almost to scales. The plant contains a sticky juice and the long roots penetrate very deeply into the soil in search of moisture.

The flower heads of Skeleton Weed are borne singly on the ends of the stems. The flowers in these heads are all of the ray type and there are usually only five pink rays in each cluster. The fruits have a tuft of pale brownish hairs which aids in their dissemination.

The wiry nature, smallness of leaf surface, and the deep root system of the Skeleton Weed make it xerophitic or drought tolerant and it thrives

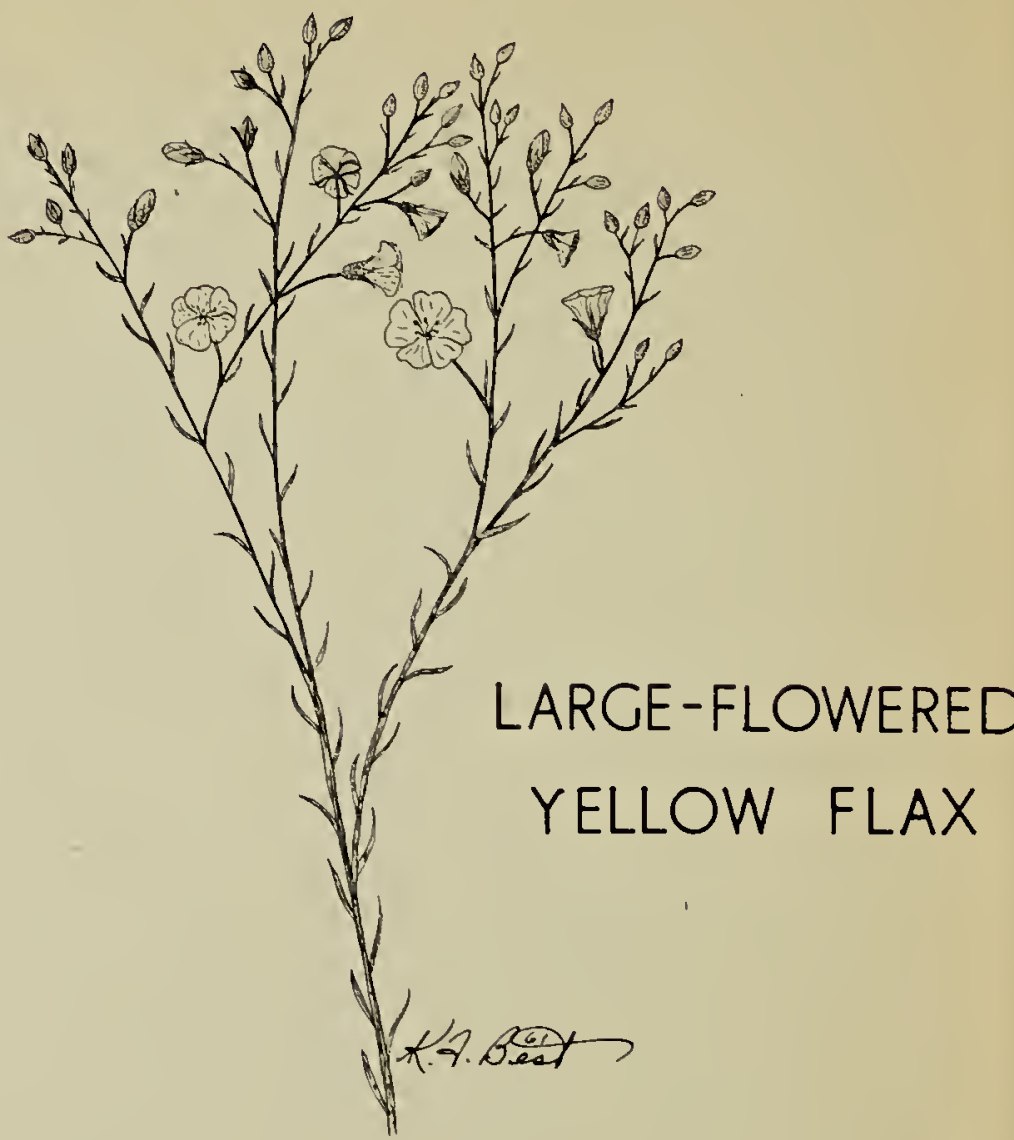

even in the driest seasons and locations in this, its native habitat.

A member of the flax family, the Large-flowered Yellow Flax (Linum rigidum) is also a species of very light, sandy soil. It is somewhat similar to the Common Wild Flax (Linum lewisii), but it has yellow instead of, b!ue flowers. This erect pale green perennial grows from 6 to 18 inches in height. The stem is simple below and somewhat branched above. The foliage is sparse. The leaves, from $1 / 3$ to 1 inch long, are linear and are easily knocked off. The bright yellow flowers are about 1 inch across and the petals, as in most of the genus, are readily shed. A shorter, more branched plant with slightly smaller flowers, found in less sandy habitats, was formerly distinguished as $L$. compactum but is is now usually included in $L$. rigidum.

\section{PRAIRIE}

SEE PAGE 120 